Semicond. Sci. Technol. v.26,

095016 (2011)

\title{
Deep level transient spectroscopic study of oxygen implanted melt grown $\mathrm{ZnO}$ single crystal
}

Z. R. Ye, X. H. Lu, G. W. Ding, S. Fung and C. C. Ling

Department of Physics, The University of Hong Kong, Pokfulam Road, Hong Kong, P. R. China

G. Brauer and W. Anwand

Institut für Strahlenphysik, Helmholtz-Zentrum Dresden-Rossendorf, Postfach 510119, D-01314 Dresden, Germany

\section{ABSTRACT}

Deep level traps in melt grown $\mathrm{ZnO}$ single crystal created by oxygen implantation and subsequent annealing in air were studied by deep level transient spectroscopy measurement between $80 \mathrm{~K}$ and $300 \mathrm{~K}$. The $\mathrm{E}_{\mathrm{C}}-0.29 \mathrm{eV}$ trap (E3) was the dominant peak in the as-grown sample and no new defects were created in the as-O-implanted sample. The single peak feature of the DLTS spectra did not change with the annealing temperature up to $750^{\circ} \mathrm{C}$, but the activation energy decreased to $0.22 \mathrm{eV}$. This was explained in terms of a thermally induced defect having a peak close to but inseparable from the original $0.29 \mathrm{eV}$ peak. A systematic study on a wide range of the rate window for the DLTS measurement successfully separated the Arrhenius plot data originated from different traps. It was inferred that the E3 concentration in the samples did not change after the O-implantation. The traps at $\mathrm{E}_{\mathrm{C}}-0.11 \mathrm{eV}, \mathrm{E}_{\mathrm{C}}-0.16 \mathrm{eV}$ and $\mathrm{E}_{\mathrm{C}}-0.58 \mathrm{eV}$ were created after the annealing. The $\mathrm{E}_{\mathrm{C}}-0.16 \mathrm{eV}$ trap was assigned to an intrinsic defect. No DLTS signal was found after the sample was annealed to $1200^{\circ} \mathrm{C}$. 


\section{Introduction}

$\mathrm{ZnO}$ is a semiconductor having a wide direct band gap $(\sim 3.3 \mathrm{eV}$ at room temperature) which has recently attracted a great deal of attention because of its applications in short wavelength optoelectronic devices, spintronic devices, high power and high temperature devices, transparent electronic and further applications [1-4].

Reliable techniques for carrying out $\mathrm{n}$ and $\mathrm{p}$-type doping are essential for fabricating semiconductor devices. Despite the asymmetric difficulty in the conductivity doping of $\mathrm{ZnO}$, p-type $\mathrm{ZnO}$ was obtained through Group-V element doping (N, As, $\mathrm{P}$ and $\mathrm{Sb}$ ) and Group III-V element co-doping [5].

Ion implantation is a technology frequently used in material and device processing. Selective area doping is one of the advantages of the ion-implantation technology. There have been reports on p-type $\mathrm{ZnO}$ layer fabrication achieved by ion implantation [6-16]. However, some workers reported highly resistive n-type material after ion-implantation and subsequent annealing (for example, [12-15]). The ion implantation process would inevitably create undesirable defects and some of these defects would persist even upon a high temperature annealing process. These would include deep traps which would compensate the material.

Other than introducing electrical doping into the $\mathrm{ZnO}$ material, 'magnetic doping' of $\mathrm{ZnO}$ could also be achieved by transition metal implantation. Room temperature ferromagnetism was reported in $\mathrm{ZnO}$ after ion implantation of $\mathrm{Co}, \mathrm{Ni}, \mathrm{C}$ and $\mathrm{Fe}$ [16-21], though the mechanism was not yet well understood. Hong et al [22] and 
Liu et al [23] have pointed out the influence of intrinsic defects on the magnetic property of transition metal doped $\mathrm{ZnO}$.

All these aspects indicate the importance of a thorough understanding of defects in $\mathrm{ZnO}$ for the development of the corresponding ion-implantation technology. However, the defects in $\mathrm{ZnO}$ are still not well understood and many controversies remain.

In the present study, deep level transient spectroscopy (DLTS) was used to study the deep traps induced in the melt grown $\mathrm{ZnO}$ single crystal induced by O-implantation. Thermal evolution of the deep traps upon annealing in air was also studied. The rate window $(\Delta \mathrm{t})^{-1}$ dependence for the DLTS spectra was studied systemically over a wide range from $\Delta \mathrm{t}=0.086-430 \mathrm{~ms}$.

\section{EXPERIMENTAL}

The $\mathrm{ZnO}$ starting material was a single side polished melt grown n-type, nominally undoped $\mathrm{ZnO}$ single crystal $\left(10 \times 10 \times 0.5 \mathrm{~mm}^{3}\right)$ obtained from Cermet Inc. with an electron concentration of $8 \times 10^{16} \mathrm{~cm}^{-3}$ and an electron mobility of $217 \mathrm{~cm}^{2} \mathrm{~V}^{-1} \mathrm{~s}^{-1}$

The samples from this material were implanted by oxygen ions on the polished side. The energy of implantation was $150 \mathrm{keV}$ and the fluence was $10^{14} \mathrm{~cm}^{-2}$. The samples were kept at temperature of $300^{\circ} \mathrm{C}$ during the implantation. TRIM [24] calculation showed that this resulted in an O-implantation profile with the peak at $\sim 280 \mathrm{~nm}$. 
The isochronal annealing step was carried out in a tube furnace in air for a period of 30 minutes. After the annealing, contacts for DLTS measurement were fabricated. The large area Ohmic contact was fabricated by evaporating a 50nm Al film onto the non-polished side of the sample. The Schottky contact was fabricated onto the ion-implanted side of the sample by evaporating $\mathrm{Au}$ contacts with a thickness of $50 \mathrm{~nm}$ after pre-treatment by hydrogen peroxide (details are given in references $[25,26])$.

DLTS measurements were carried out on these samples across the Schottky and the Ohmic contacts. The contact quality was verified by the $\mathrm{I}-\mathrm{V}$ and $\mathrm{C}-\mathrm{V}$ measurements carried out on each of the diodes using the HP4145A semiconductor parameter analyzer and the HP4275A multi-frequency LCR meter, respectively. The DLTS measurements were performed using the Sula DLTS system with temperature varying from $80 \mathrm{~K}$ to $300 \mathrm{~K}$.

The electron emission rate $e_{n}$ from the trap is given by:

$$
e_{n}=\sigma_{n} v_{t h} N_{C} \exp \left[-\left(E_{C}-E_{a}\right) / k T\right]
$$

where $\sigma_{n}$ and $E_{a}$ are the capture cross section and the activation energy of the deep trap, respectively. $\quad N_{C}$ and $v_{t h}$ are the state density of the conduction band and the velocity of free electron, respectively. As $v_{t h} \sim T^{1 / 2}$ and $\sigma_{n} \sim T^{3 / 2}$ holds, the values of $E_{a}$ and $\sigma_{n}$ were obtained from the linear fitting of the Arrhenius plot $\ln \left(e_{n} / T^{2}\right)$ as a function of $T^{1}$ [27]. The concentration of the trap $N$ was related to the $\Delta C / C_{0}$ by:

$$
N_{T}=2 N_{d} \frac{\Delta C}{C_{0}}
$$

where $N_{d}$ is the donor concentration, $\Delta C$ is the capacitance transient produced with the 
rate winodow $(\Delta \mathrm{t})^{-1}$ and the applied reverse bias of $V_{R}$ during the emission period, and $\mathrm{C}_{0}$ is the equilibrium junction capacitance with the reverse bias of $V_{R}$.

\section{RESULTS AND DISCUSSIONS}

DLTS spectra from unimplanted samples were obtained as control. For the as-grown sample, the DLTS spectra had a dominant peak having the activation energy, capture cross section and trap density of $E_{a}=0.31 \mathrm{eV}, \sigma_{n} \sim 10^{-16} \mathrm{~cm}^{2}$, and $N_{T} \sim 10^{15}$ $\mathrm{cm}^{-3}$, respectively. This trap has parameters agreeing with the commonly found deep trap $\mathrm{E} 3$ in $\mathrm{ZnO}$ materials $[10,15,28-35]$. Another peak with $E_{a}=0.10 \mathrm{eV}, \sigma_{n} \sim$ $10^{-17} \mathrm{~cm}^{2}$, and $N_{T} \sim 10^{13} \mathrm{~cm}^{-3}$ was also identified with a much weaker intensity (20 times less than E3). This trap has the activation energy and the capture cross section close to the previously observed E2 trap [28,30-32]. The E3 intensity dropped with annealing temperature, but persisted at $1200{ }^{\circ} \mathrm{C}$ annealing. The $E_{a}=0.10 \mathrm{eV}$ level anneals out at $900{ }^{\circ} \mathrm{C}$.

$\mathrm{I}-\mathrm{V}$ and $\mathrm{C}-\mathrm{V}$ measurements were carried out on every sample annealed at different temperatures in order to check the quality of the rectifying contacts. The carrier concentrations for each of the samples were also calculated and are tabulated in Table I. The carrier concentration did not undergo a significant change $\left(n \sim 10^{17}\right.$ $\mathrm{cm}^{-3}$ ) after the O-implantation, and post-implantation annealing up to $900^{\circ} \mathrm{C}$. However, the $1200^{\circ} \mathrm{C}$ post-implantation annealing increased the carrier concentration to $\sim 10^{18} \mathrm{~cm}^{-3}$.

DLTS spectra of the O-implanted samples were obtained between $80 \mathrm{~K}$ and $300 \mathrm{~K}$ 
in as-O-implanted state, and after different post-implantation annealing $\left(350^{\circ} \mathrm{C}, 650^{\circ} \mathrm{C}\right.$, $\left.750^{\circ} \mathrm{C}, 1200^{\circ} \mathrm{C}\right)$. The reverse bias, filling pulse voltage and period were fixed at $\mathrm{V}_{\mathrm{R}}=-1 \mathrm{~V}, \mathrm{~V}_{\mathrm{p}}=0 \mathrm{~V}$, and $\mathrm{t}_{\mathrm{p}}=1 \mathrm{~ms}$, respectively, for all the DLTS measurements, while the rate window $(\Delta \mathrm{t})^{-1}$ varied over a wide range from $\Delta \mathrm{t}=0.086 \mathrm{~ms}$ to $430 \mathrm{~ms}$. The application of $\mathrm{V}_{\mathrm{R}}=-1 \mathrm{~V}$ to the sample with $\mathrm{n}=10^{17} \mathrm{~cm}^{-3}$ (i.e. the O-implanted samples with annealing temperature $\leq 900^{\circ} \mathrm{C}$ ) implied a depletion width of $\sim 120 \mathrm{~nm}$, which was within the oxygen implanted region as determined by the TRIM simulation and the SIMS measurement. For the sample annealed at $1200^{\circ} \mathrm{C}$, the corresponding depletion width dropped to $38 \mathrm{~nm}$ as the carrier concentration increased to $\sim 10^{18} \mathrm{~cm}^{-3}$.

For the samples annealed at temperatures $\leq 750^{\circ} \mathrm{C}$, the corresponding DLTS spectra contained a single major carrier peak, implying that the corresponding deep trap was an electron trap. One such typical spectrum series with different $\Delta \mathrm{t}^{\prime} \mathrm{s}$ is illustrated by the spectra obtained from the sample annealed at $750^{\circ} \mathrm{C}$ and is shown in Figure 1(a). The peaking temperatures and the heights of the DLTS peaks increased with decreasing $\Delta \mathrm{t}$. The DLTS spectra of the $900^{\circ} \mathrm{C}$ annealed sample taken with different $\Delta \mathrm{t}$ 's are shown in Figure 1(b), from which three peaks, namely labeled as Peak 1, 2 and 3, were observed. Peak 1 had a much weaker intensity than the other two. For the $1200^{\circ} \mathrm{C}$ annealed sample, no peak was observed in all the DLTS spectra taken with different rate windows.

The corresponding Arrhenius plots of the DLTS spectra obtained from the as-O-implanted, $750^{\circ} \mathrm{C}$ and $900^{\circ} \mathrm{C}$ annealed samples are shown in Figure 2(a). The activation energy $E_{a}$ of each trap from the different samples was obtained by carrying 
out the linear fitting to the Arrhenius plots according to equation (1). The results are shown in Figure 3.

From Figure 3, a single trap with $\mathrm{E}_{\mathrm{a}} \sim 0.29 \mathrm{eV}$ was identified in the as-O-implanted sample. It was found that its $E_{a}$ decreases with increasing annealing temperature and drops to a value of $0.22 \mathrm{eV}$ at $750^{\circ} \mathrm{C}$ annealing temperature. After further increase of the annealing temperature to $900^{\circ} \mathrm{C}$, three peaks with $\mathrm{E}_{\mathrm{a}}$ 's of $0.11 \mathrm{eV}, 0.16 \mathrm{eV}$ and $0.37 \mathrm{eV}$, respectively, were observed.

It is also noticed that the Arrhenius plot data of the $750^{\circ} \mathrm{C}$ and the peak 3 of the $900^{\circ} \mathrm{C}$ data significantly deviate from the straight lines obtained from the linear fitting process. However for the as-O-implanted sample, the fitting straight line fitted excellently well with the experimental data. This was clearly illustrated in figure 2(b), which showed the Arrhenius plots of the relevant peaks in a larger scale.

It is worth investigating the drop of the activation energy for the $0.29 \mathrm{eV}$ trap, as identified in the as-O-implanted sample, when the annealing temperature increases. One possible explanation was that a new trap having a peaking temperature close to that of the $0.29 \mathrm{eV}$ trap was formed by thermal annealing, and the resultant observed peak is the unresolved combination of the two signals.

The DLTS measurement was performed by monitoring the DLTS signal (i.e. the $\Delta \mathrm{C} / \mathrm{C}$ signal) at different temperatures while temporarily fixing the rate window. For a fixed rate window, each of the traps would have its carrier emission dominant at different temperature, and thus is revealed by a peak in the DLTS spectrum. The peaking temperature is dependent on the trap's emission rate $e_{n}$, activation energy $E_{a}$, 
capture cross section $\sigma_{\mathrm{n}}$, and the rate window adopted. The Arrhenius plot data for a trap can thus be obtained by monitoring the peaking temperatures with the rate window being varied. Two traps (with different $E_{a} s$ ) having their peaking temperatures too close to be separated would have their emissions dominant at different temperatures. For example for the Arrhenius plots of the $750^{\circ} \mathrm{C}$ annealed samples (figure 2(b)), the data at the lower temperature region (i.e. 1000/T>5.2) corresponded to the emission dominantly contributed from the trap with the lower Ea, and those at the higher temperature region $(1000 / \mathrm{T}<5.2)$ represented those from the trap having a higher $\mathrm{E}_{\mathrm{a}}$.

In figure 2(b), the as-O-implanted sample data were well fitted by a straight line with $\mathrm{E}_{\mathrm{a}}=0.29 \mathrm{eV}$. For the data of the $750^{\circ} \mathrm{C}$ annealed sample, the data could only be well fitted by two straight lines with the breaking point at 1000/T 5.2 and the cprresponding $\mathrm{E}_{\mathrm{a}}$ 's were $0.16 \mathrm{eV}$ and $0.29 \mathrm{eV}$. Similar two segment line fitting was also carried out on the Arrhenius data of peak 3 for the $900^{\circ} \mathrm{C}$ annealed sample with the breaking point at $1000 / \mathrm{T} \sim 5.8$, wihch yielded the $\mathrm{E}_{\mathrm{a}}$ values of $0.30 \mathrm{eV}$ and $0.58 \mathrm{eV}$ respectively. The two fitted lines also well described the data (figure 2(b))..

The present observation thus suggests that only one trap with $E_{a}=0.29 \mathrm{eV}$ exists in the as-O-implanted and the $350^{\circ} \mathrm{C}$ annealed samples. However, if the annealing temperature is increased to $750^{\circ} \mathrm{C}$, the observed $0.22 \mathrm{eV}$ peak was indeed the combined signal from the $0.29 \mathrm{eV}$ and the $0.16 \mathrm{eV}$ trap, respectively. And if the sample was annealed at $900^{\circ} \mathrm{C}$, two unambiguously separated peaks 1 and 2 having an $\mathrm{E}_{\mathrm{a}}$ of $0.11 \mathrm{eV}$ and $0.16 \mathrm{eV}$, respectively, were identified. In addition, the observed 
$0.37 \mathrm{eV}$ peak consisted of the $0.30 \mathrm{eV}$ trap and the $0.58 \mathrm{eV}$ trap, respectively. These findings of the DLTS study in O-implanted $\mathrm{ZnO}$ samples are summarized in Table I as well.

A similar DLTS study was also performed on the Schottky contact formed on an n-type $\mathrm{N}$-implanted $\mathrm{ZnO}$ sample. The nitrogen implantation process involved a 4-folded implantation with energies of $80,180,310$ and $500 \mathrm{keV}$, which produced a $1 \mu \mathrm{m}$-depth box-shaped region with a nitrogen concentration of $\sim 6 \times 10^{18} \mathrm{~cm}^{-3}$. A similar trap with $\mathrm{E}_{\mathrm{a}}=0.31 \mathrm{eV}$ was also identified in the as-nitrogen-implanted sample. The annealing behavior of its $\mathrm{E}_{\mathrm{a}}$ is included in Figure 3 for comparison to demonstrate that a similar drop of $\mathrm{E}_{\mathrm{a}}$ from $0.31 \mathrm{eV}$ to $0.25 \mathrm{eV}$ in the $750^{\circ} \mathrm{C}$ annealed sample was also observed after $\mathrm{N}$-implantation. Moreover it was worthy to point out that as compared to the TRIM simulated O-implanted depth profile peaking at $\sim 280 \mathrm{~nm}$, the $120 \mathrm{~nm}$ depletion width corresponding to the reverse bias $\mathrm{V}_{\mathrm{R}}=-1 \mathrm{~V}$ during the emission period only barely overlapped the O-ion implantation. It was thus plausible to suggest that the induced defects were formed primarily by the kinetic of vacancy and knock-on in this depletion rather than with the involvement of the implanted oxygen.

The $\sim 0.29 \mathrm{eV}$ trap $\left(\sigma \sim 10^{-16} \mathrm{~cm}^{2}\right)$ found in the as-grown sample and the O-implanted samples had $E_{a}$ and $\sigma_{n}$ in good agreement with those values of the previously reported deep trap E3 [28,30,32]. E3 is the deep trap commonly found in $\mathrm{ZnO}$ materials irrespective of the growth method. In the present study, E3 was the major deep trap found in the as-received melt grown sample having $\mathrm{N}_{\mathrm{T}} \sim 10^{15} \mathrm{~cm}^{-3}$. Its density remained unchanged with the O-implantation and the subsequent thermal 
annealing up to $900^{\circ} \mathrm{C}$. The E3 deep trap has been suggested to be associated with the oxygen vacancy [28] and the zinc interstitial $\mathrm{Zn}_{\mathrm{i}}[30,32]$ though no concrete agreement has been reached.

The $0.16 \mathrm{eV}$ trap $\left(\sigma \sim 10^{-17}-10^{-18} \mathrm{~cm}^{2}\right)$ was observed in the $750^{\circ} \mathrm{C}$ and the $900^{\circ} \mathrm{C}$ post-O-implantation annealed samples. Its concentration was $\sim 10^{16} \mathrm{~cm}^{-3}$ in both the $750^{\circ} \mathrm{C}$ and $900^{\circ} \mathrm{C}$ annealed samples. A trap having similar $\mathrm{E}_{\mathrm{a}}(=0.17-0.18 \mathrm{eV})$ and $\sigma$ $\left(\sim 10^{-16} \mathrm{~cm}^{2}\right)$ was also identified in the annealed nitrogen implanted $\left(150 \mathrm{keV}, 10^{14} \mathrm{~cm}^{-2}\right)$ melt grown $\mathrm{ZnO}$ samples of our previous study [26], in which the ion-implantation process, annealing process and raw material used were similar to the present study. These two traps are probably the same, i.e. connected to the same lattice defect. We have also carried out DLTS study on electron irradiated $\left(1.8 \mathrm{MeV}, 10^{15} \mathrm{~cm}^{-2}\right)$ melt grown $\mathrm{ZnO}$ samples with the similar raw material and annealing condition. For the $200^{\circ} \mathrm{C}, 350^{\circ} \mathrm{C}$ and $750^{\circ} \mathrm{C}$ annealed electron irradiated samples, the DLTS spectra contained two well-separated peaks representing traps having $\mathrm{E}_{\mathrm{a}}=0.16-0.18 \mathrm{eV}$ $\left(\sigma \sim 10^{-17} \mathrm{~cm}^{2}\right)$ and $E_{a}=0.28-0.30 \mathrm{eV}\left(\sigma \sim 10^{-16} \mathrm{~cm}^{2}\right)$. It can be concluded that the $0.16 \mathrm{eV}$ trap was created in O-implanted melted grown $\mathrm{ZnO}$ single crystal after annealing in air at $750^{\circ} \mathrm{C}$, as well as in the electron irradiated samples. As its thermally induced generation was independent of the species of irradiation, this trap should be an intrinsic defect.

In the present study, the $0.58 \mathrm{eV}\left(\sigma \sim 10^{-17} \mathrm{~cm}^{2}\right)$ trap was identified in the $900^{\circ} \mathrm{C}$ annealed sample with a concentration of $\sim 10^{16} \mathrm{~cm}^{-3}$. Its activation energy is close to that of the E4 trap having $\mathrm{E}_{\mathrm{a}}=0.57 \mathrm{eV}$ and $\sigma \sim 10^{-12} \mathrm{~cm}^{2}$ [28]. $\mathrm{E} 4$ has been assigned to 
the oxygen vacancy [30]. However, the $0.58 \mathrm{eV}$ found in the present study had a capture cross section of $\sigma \sim 10^{-17} \mathrm{~cm}^{2}$ only, which is much smaller than the generally accepted value of $\sim 10^{-12} \mathrm{~cm}^{2}$ of $E 4$.

In hydrothermally grown $\mathrm{ZnO}$, Vine et al [33] have identified a $0.58 \mathrm{eV}$ trap having a $\sigma \sim 10^{-16} \mathrm{~cm}^{2}$. In a nitrogen implanted and thermally annealed pulsed laser deposition grown $\mathrm{ZnO}$ sample, Schmidt et al [35] observed a $0.58 \mathrm{eV}$ trap having a $\sigma \sim 10^{-15} \mathrm{~cm}^{2}$ (TN1). It was further argued in ref. [35] that because of the much smaller capture cross section this trap was distinguished from the E4 trap, and is related to nitrogen. The $0.58 \mathrm{eV}$ trap, as identified in the present study, is more likely identical with the defect described by Vine et al [33] and Schmidt et al [35] rather than the trap E4, if based on the consideration of the capture cross section.

A $0.11 \mathrm{eV}\left(\sigma \sim 10^{-18} \mathrm{~cm}^{2}\right)$ trap having a concentration of $\sim 10^{15} \mathrm{~cm}^{-3}$ was well separated from the $900^{\circ} \mathrm{C}$ annealed sample spectra (Peak 1 in figure 1(b)). Its activation energy and capture cross section are close to those values of the E2 trap $\left(E_{a}=0.10 \mathrm{eV}, \sigma \sim 10^{-17} \mathrm{~cm}^{2}\right)$ identified in the as-grown sample, and was thus assigned to E2. Our observation thus showed that the $900^{\circ} \mathrm{C}$ annealing would enhance the E2 concentration from $10^{13} \mathrm{~cm}^{-3}$, as found in the as-grown sample, to $10^{15} \mathrm{~cm}^{-3}$.

No trap was identified in the $1200^{\circ} \mathrm{C}$ annealed sample irrespective of the rate window. This could imply that all the traps were annealed out (i.e. with concentration below $\sim 10^{14} \mathrm{~cm}^{-3}$ ) at this temperature. However, it should be noted that the reduction of the DLTS signals could be a result of the increased carrier concentration induced by the $1200^{\circ} \mathrm{C}$ annealing. When fixing the reverse bias during 
the DLTS measurements at $V_{R}=-1 \mathrm{~V}$, the corresponding depletion region width dropped from $\sim 120 \mathrm{~nm}$ for the $900^{\circ} \mathrm{C}$ annealed sample to $\sim 38 \mathrm{~nm}$ for the $1200^{\circ} \mathrm{C}$, whereas the carrier concentration increased from $\sim 10^{17} \mathrm{~cm}^{-3}$ to $\sim 10^{18} \mathrm{~cm}^{-3}$. As the O-implantation profile had a maximum at $\sim 280 \mathrm{~nm}$, a shrinking of the depletion region to the $\mathrm{Au} / \mathrm{ZnO}$-interface adjacent tail of the implantation profile could result in a reduction of the corresponding DLTS signal.

It is worthy to discuss the limitation of the present study, for which the multi-component peaks were not unambiguously resolved in the DLTS spectra. We have indeed attempted to resolve these peaks by varying the measuring parameters of the DLTS and carrying out Gaussian fitting to the multi-component peak. However we failed to produce a peak separated DLTS spectrum, nor obtain a Gaussian fitting with sufficient statistical certainty. Particular attention would be placed in discussing the Peak 3 found in the $900^{\circ} \mathrm{C}$ annealed sample spectrum. If the peak was fitted with the single component model according to equation (1), it has the $\mathrm{E}_{\mathrm{a}}=0.37 \mathrm{eV}$ and the capture cross section $\sigma=2 \times 10^{13} \mathrm{~cm}^{2}$. From our argument, its Arrhenius plot was fitted separately in two temperature regions and it was concluded to compose of two traps having $\mathrm{E}_{\mathrm{a}}$ 's of $0.30 \mathrm{eV}$ and $0.58 \mathrm{eV}$. It is noticed that the fitted $\mathrm{E}_{\mathrm{a}}$ of $0.37 \mathrm{eV}$ coincided with the trap $\mathrm{E} 3$ ' reported previously in $\mathrm{ZnO}$ materials [36]. However, the E3' has a capture cross section of $\sigma=7 \times 10^{-15} \mathrm{~cm}^{2}$ which differs significantly from that of Peak 3 and thus Peak 3 was not originated from the trap E3'.

\section{CONCLUSION}


A DLTS study was carried out on O-implanted melt grown $\mathrm{ZnO}$ single crystal samples. The $\mathrm{E}_{\mathrm{C}}-0.30 \mathrm{eV}$ (E3) was the major trap identified in the as-grown sample. The O-implantation process did not create any new deep trap. However, the post-implantation annealing process in air created traps at $\mathrm{E}_{\mathrm{C}}-0.16 \mathrm{eV}$ and $\mathrm{E}_{\mathrm{C}}-0.58 \mathrm{eV}$, respectively, and enhanced the concentration of the E2 trap. The $0.16 \mathrm{eV}$ trap is an intrinsic defect.

\section{ACKNOWLEDGEMENTS}

This work was supported by the GRF (7031/08P) awarded by the Research Grant Council, HKSAR; the Small Project Grant and the University Development Fund awarded by The University of Hong Kong. 


\section{REFERENCES:}

[1] Zinc Oxide Bulk, Thin Films and Nanostructures Processing, Properties and Applications, edited by C. Jagadish and Ss. J. Pearton (Elsevier, New York, 2006).

[2] Ü. Özgür, Ya. I. Alivov, C. Liu, A. Teke, M. A. Reshchikov, S. Doğan, V. Avrutin, S.-J. Cho and H. Morkoç, J. Appl. Phys. 98, 041301 (2005).

[3] S. J. Pearton, D. P. Norton, K. Ip, Y. W. Heo and T. Steiner, J. Vac. Sci. Technol. B 22, 932 (2004).

[4] D. C. Look, J. Electron. Mater. 35, 1299 (2006).

[5] V. Avrutin, D. J. Silversmith and H. Morkoç, Proc. IEEE 98, 1269 (2010).

[6] A. N. Georgobiani, A. N. Gruzintsev, V. T. Volkov, M. O. Vorobiev, V. I. Demin and V. A.Dravin, Nucl. Inst. Meth. Phys. Res. A 514, 117 (2003).

[7] C. C. Lin, S. Y. Chen, S. Y. Cheng, and H. Y. Lee, Appl. Phys. Lett. 84, 5040 (2004).

[8] H. von Wenckstern, R. Pickenhain, H. Schmidt, M. Brandt, G. Biehne, M. Lorenz, M. Grundmann and G. Brauer, Appl. Phys. Lett. 89, 092122 (2006).

[9] H. T. Wang, B. S. Kang, J. J. Chen, T. Anderson, S. Jang, F. Ren, H. S. Kim, Y. J. Li, D. P. Norton and S. J. Pearton, Appl. Phys. Lett. 88, 102107 (2006).

[10] Q. L. Gu, C. C. Ling, G. Brauer, W. Anwand, W. Skorupa, Y. F. Hsu, A. B. Djurišić, C. Y. Zhu, S. Fung and L. W. Lu, Appl. Phys. Lett. 92, 222109 (2008).

[11] G. Braunstein, A. Muraviev, H. Saxena, N. Dhere, V. Richter and R. Kalish, Appl. Phys. Lett. 87, 192103 (2005).

[12] X. D. Chen, C. C. Ling, S. Fung, C. D. Beling, Y. F. Mei, R. K. Y. Fu, G. G. 
Siu and P. K. Chu, Appl. Phys. Lett. 88, 132104 (2006).

[13] V. Vaithianathan, S. Hishita, J. Y. Park, S. S. Kim, J. Appl. Phys. 102, 086107 (2007).

[14] X. D. Zhang, C. L. Liu, Z. Wang, Y. Y. Lu and L. J. Yin, Nucl. Inst. Meth. Phys. Res. B 254, 83 (2007).

[15] C. Y. Zhu, C. C. Ling, G. Brauer, W. Anwand and W. Skorupa, Microelectron. J. 40, 286 (2009).

[16] K. Potzger, S. Q. Zhou, H. Reuther, A. Mücklich, F. Eichhorn, N. Schell, W. Skorupa, M. Helm, J. Fassbender, T. Hermannsdörfer, T. P. Papageorgiou, Appl. Phys. Lett. 88, 052508 (2006).

[17] M. Shuai, L. Liao, H. B. Lu, L. Zhang, J. C. Li, D. J. Fu, J. Phys. D 41, 135010 (2008).

[18] S.Q. Zhou, Q Y. Xu, K. Potzger, G. Talut, R. Grötzschel, J. Fassbender, M. Vinnichenko, J. Grenzer, M. Helm, H. Hochmuth, M. Lorenz, M. Grundmann, H. Schmidt, Appl. Phys. Lett. 93, 232507 (2008).

[19] K. Potzger, S. Q. Zhou, Q. Y. Xu, A.Shalimov, R. Groetzschel, H. Schmidt, A. Mücklich, M. Helm, J. Fassbender, Appl. Phys. Lett. 93, 232504 (2008).

[20] B. Pandey, S. Ghosh, P. Srivastava, P. Kumar, D. Kanjilal, J. Appl. Phys. 105, 033909 (2009).

[21] N. Akdogan, H. Zabel, A. Nefedov, K. Westerholt, H. W. Becker, S. Gok, R. Khaibullin and L. Tagirov, J. Appl. Phys. 105, 043907 (2009).

[22] N. H. Hong, J. Sakai, N T. Nuong, N. Poirot and A. Ruyter, Phys. Rev. B 72, 
$045336(2005)$.

[23] H. Liu, X. Zhang, L. Li, Y. X. Wang, K. H. Gao, Z. Q. Li, R. K. Zheng, S. P. Ringer, B. Zhang and X. X. Zhang, Appl. Phys. Lett. 91, 072511 (2007).

[24] J. F. Ziegler, J. P. Biersack, and U. Littmark, The stopping and range of ions in solids, (Pergamon, New York, 1985).

[25] Q. L. Gu, C. C. Ling, X. D. Chen, C. K. Cheung, A. M. C. Ng, C. D. Beling, S. Fung, A. B. Djurišić, L. W. Lu, G. Brauer and H. C. Ong, Appl. Phys. Lett. 90, 122101 (2007).

[26] Q. L. Gu, C. K. Cheung, C. C. Ling, A. M. C. Ng, A. B. Djurišić, L. W. Lu, X. D. Chen, S. Fung, C. D. Beling and H. C. Ong, J. Appl. Phys. 103, 093706 (2008).

[27] D. V. Lang, J. Appl. Phys. 45, 3023 (1974).

[28] F. D. Auret, S. A. Goodman, M. J. Legodi, W. E. Meyer, D. C. Look, Appl. Phys. Lett. 80, 1340 (2002).

[29] F. D. Auret S. A. Goodman, M. Hayes, M. J. Legodi, H. A. van Laarhoven, D. C. Look, Appl. Phys. Lett. 79, 3074 (2001).

[30] T. Frank, G. Pensl, R. Tena-Zaera, J. Zúñiga-Pérez, C. Martínez-Tomás, V. Muñoz-Sanjosé, T. Ohshima, H. Itoh, D. Hoffmann, D. Pfisterer, J. Sann, B. Meyer, Appl. Phys. A 88, 141 (2007).

[31] F. C. Auret J. M. Nel, M. Hayes, L. Wu, W. Wesch, E. Wendler, Superlattices and Microstructures 39, 17 (2006).

[32] H. Frenzel, H. v. Wenckstern, A. Weber, H. Schmidt, G. Biehne, H. Hochmuth M. Lorenz and M. Grundmann, Phys. Rev. B 76, 035214 (2007). 
[33] L. Vines, E. V. Monakhov, B. G. Svensson, Physica B 404, 4386 (2009).

[34] M. Schmidt, M. Ellguth, C. Czekalla, H. von Wenckstern, R. Pickenhain, M. Grundmann, G. Brauer, W. Skorupa, M. Helm, Q. Gu and C. C. Ling, J. Vac. Sci. Technol. B 27, 1597 (2009).

[35] M. Schmidt, M. Ellguth, F. Schmidt, T. Lüth, H. V. Wenckstern, R. Pickenhain, M. Grundmann, G. Brauer, W. Skorupa, Phys. Stat. Sol. B 247, 1220 (2010).

[36] F. D. Auret, W. E. Meyer, Pl J. Janse van Rensburg, M. Hayes, J. M. Nel, H. von Wenckstern, H. Schmidt, G. Biehne, H. Hochmuth, M. Lorentz and M. Grundmann, Physica B 401-402 378 (2007). 
TABLE 1 Tabulated carrier concentration $n$ of the O-implanted samples annealed at different temperatures as obtained by the $\mathrm{C}-\mathrm{V}$ method. The estimated energy level with respect to the conduction band $E_{C}$, the capture cross section $\sigma$ and the concentration $\mathrm{N}_{\mathrm{T}}$ of the deep level traps identified are given also.

\section{Oxygen-implanted ZnO samples}

\begin{tabular}{|c|c|c|c|c|}
\hline $\begin{array}{l}\text { As-O-implanted } \\
\mathrm{n}=2 \times 10^{17} \mathrm{~cm}^{-3}\end{array}$ & $\begin{array}{l}350^{\circ} \mathrm{C} \\
\mathrm{n}=3 \times 10^{17} \mathrm{~cm}^{-3}\end{array}$ & $\begin{array}{l}750^{\circ} \mathrm{C} \\
\mathrm{n}=1 \times 10^{17} \mathrm{~cm}^{-3}\end{array}$ & $\begin{array}{l}900^{\circ} \mathrm{C} \\
\mathrm{n}=4 \times 10^{17} \mathrm{~cm}^{-3}\end{array}$ & $\begin{array}{l}1200^{\circ} \mathrm{C} \\
\mathrm{n}=1 \times 10^{18} \mathrm{~cm}^{-3}\end{array}$ \\
\hline \multirow[t]{4}{*}{$\begin{array}{l}\mathrm{E}_{\mathrm{C}^{-}} 0.29 \mathrm{eV} \\
\left(\sigma \sim 10^{-16} \mathrm{~cm}^{2,},\right. \\
\left.\mathrm{N}_{\mathrm{T}}=10^{15} \mathrm{~cm}^{-3}\right)\end{array}$} & $\begin{array}{l}\mathrm{E}_{\mathrm{C}^{-}}-0.29 \mathrm{eV} \\
\left(\sigma \sim 10^{-16} \mathrm{~cm}^{2},\right. \\
\left.\mathrm{N}_{\mathrm{T}}=10^{15} \mathrm{~cm}^{-3}\right)\end{array}$ & $\begin{array}{l}\mathrm{E}_{\mathrm{C}}-0.29 \mathrm{eV} \\
\left(\sigma \sim 10^{-15} \mathrm{~cm}^{2}\right. \\
\left.\mathrm{N}_{\mathrm{T}} \sim 10^{15} \mathrm{~cm}^{-3}\right)\end{array}$ & $\begin{array}{l}\mathrm{E}_{\mathrm{C}^{-}}-0.30 \mathrm{eV} \\
\left(\sigma \sim 10^{-15} \mathrm{~cm}^{2}\right. \\
\left.\mathrm{N}_{\mathrm{T}} \sim 10^{15} \mathrm{~cm}^{-3}\right)\end{array}$ & No peak \\
\hline & & $\begin{array}{l}\mathrm{E}_{\mathrm{C}}-0.16 \mathrm{eV} \\
\left(\sigma \sim 10^{-18} \mathrm{~cm}^{2}\right. \\
\left.\mathrm{N}_{\mathrm{T}} \sim 10^{16} \mathrm{~cm}^{-3}\right)\end{array}$ & $\begin{array}{l}\mathrm{E}_{\mathrm{C}}-0.16 \mathrm{eV} \\
\left(\sigma \sim 10^{-17} \mathrm{~cm}^{2}\right. \\
\left.\mathrm{N}_{\mathrm{T}} \sim 10^{16} \mathrm{~cm}^{-3}\right)\end{array}$ & \\
\hline & & & $\begin{array}{l}\mathrm{E}_{\mathrm{C}}-0.11 \mathrm{eV} \\
\left(\sigma \sim 10^{-18} \mathrm{~cm}^{2}\right. \\
\left.\mathrm{N}_{\mathrm{T}} \sim 10^{15} \mathrm{~cm}^{-3}\right)\end{array}$ & \\
\hline & & & $\begin{array}{l}\mathrm{E}_{\mathrm{C}}-0.58 \mathrm{eV} \\
\left(\sigma \sim 10^{-17} \mathrm{~cm}^{2}\right. \\
\left.\mathrm{N}_{\mathrm{T}} \sim 10^{16} \mathrm{~cm}^{-3}\right)\end{array}$ & \\
\hline
\end{tabular}




\section{FIGURE CAPTIONS}

Figure 1 DLTS spectra of (a) the $750^{\circ} \mathrm{C}$, and (b) the $900^{\circ} \mathrm{C}$ annealed O-implanted melt grown $\mathrm{ZnO}$ samples. The spectra were taken with $\mathrm{V}_{\mathrm{R}}=-1 \mathrm{~V}, \mathrm{~V}_{\mathrm{p}}=0 \mathrm{~V}$, and $t_{\mathrm{p}}=1$ ms. The rate window $(\Delta t)^{-1}$ of the measurements varied systemically over a wide range from $\Delta \mathrm{t}=0.086 \mathrm{~ms}$ up to $430 \mathrm{~ms}$.

Figure 2 (a) Arrhenius plots of the all the peaks found in the as-O-implanted, $750^{\circ} \mathrm{C}$ annealed and $900^{\circ} \mathrm{C}$ annealed $\mathrm{ZnO}$ samples. The straight lines are obtained from the fitting assuming a single straight line and the corresponding $E_{a}$ were shown in the figure; (b) The zoomed-in of the same Arrhenius plots in the high temperature range so that the single peaks data of the as-O-implanted and $750^{\circ} \mathrm{C}$ annealed sample, as well as those of Peak 3 of the $900^{\circ} \mathrm{C}$ annealed sample were shown in a larger scale. Single straight line fitting to the data was found in the as-O-implanted sample (see dotted line). However for the $750^{\circ} \mathrm{C}$ and $900^{\circ} \mathrm{C}$ sample annealed sample data, significant deviation from single line fitting was observed (see dotted lines). The solid lines are the fitted lines assuming two temperature regions in the fitting process with details described in the text.

Figure 3 Activation energy $E_{a}$ as a function of the annealing temperature $T$ of the identified single peak in the O-implanted and the 4-folded $\mathrm{N}$-implanted samples assuming the single component peak. The drop of $E_{a}$ with increasing annealing temperature $\leq 750^{\circ} \mathrm{C}$ was the effect of the merging of an annealing induced peak 
$(0.16 \mathrm{eV})$ with the original peak with $\mathrm{E}_{\mathrm{a}} \sim-0.29 \mathrm{eV}$. New peaks were induced in the $900^{\circ} \mathrm{C}$ annealed sample spectra. The $0.37 \mathrm{eV}$ peak consisted of the $0.29 \mathrm{eV}$ and 0.58 $\mathrm{eV}$, and the other two peaks had single component. 


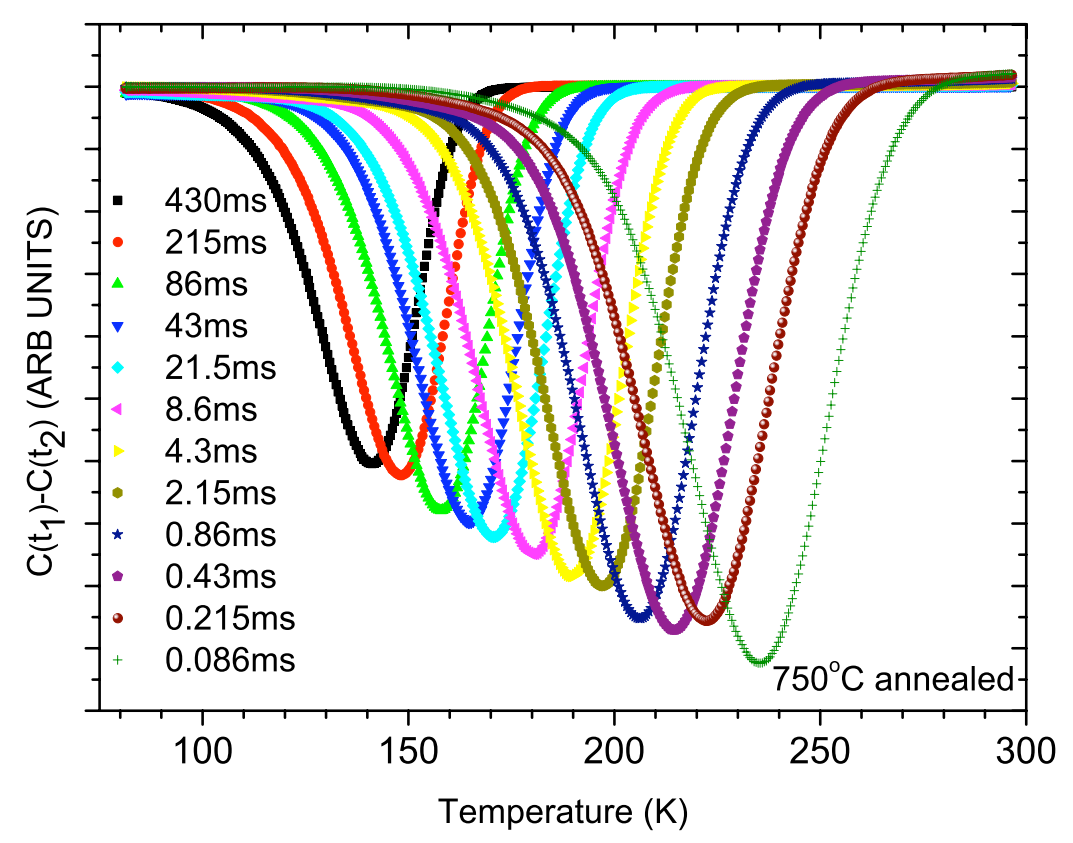

Figure1(a)

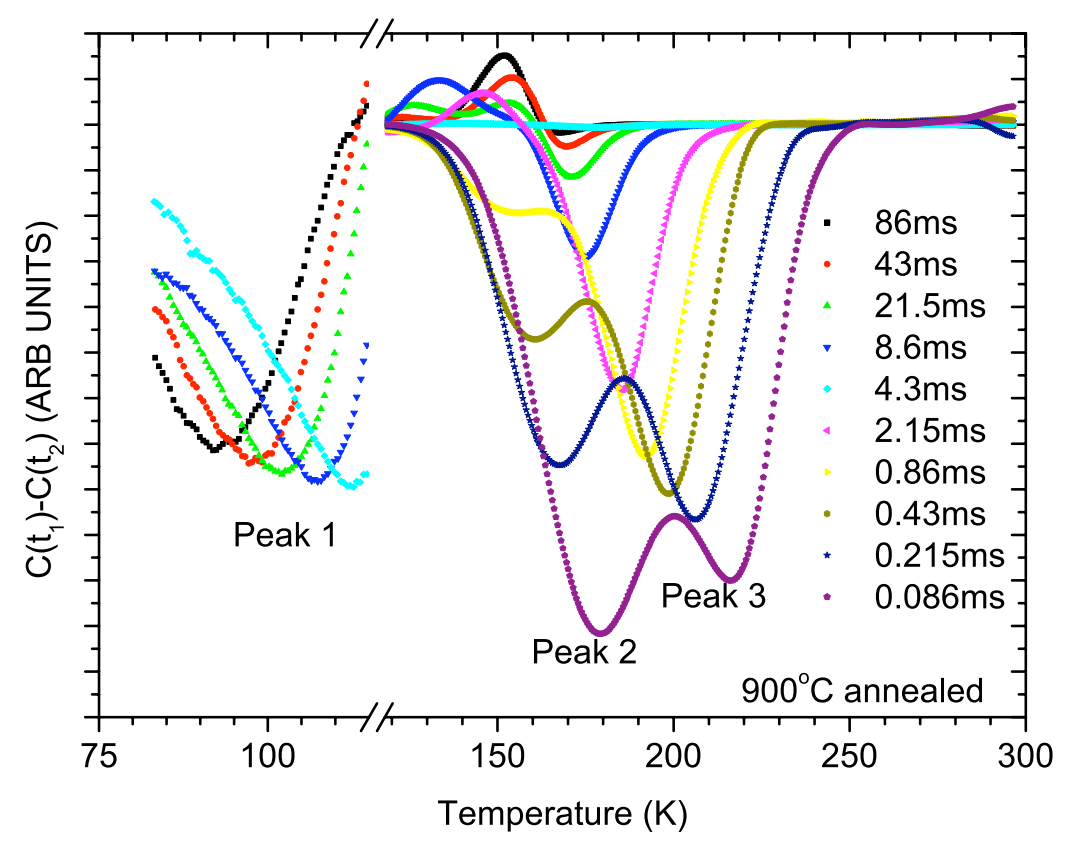

Figure 1(b) 


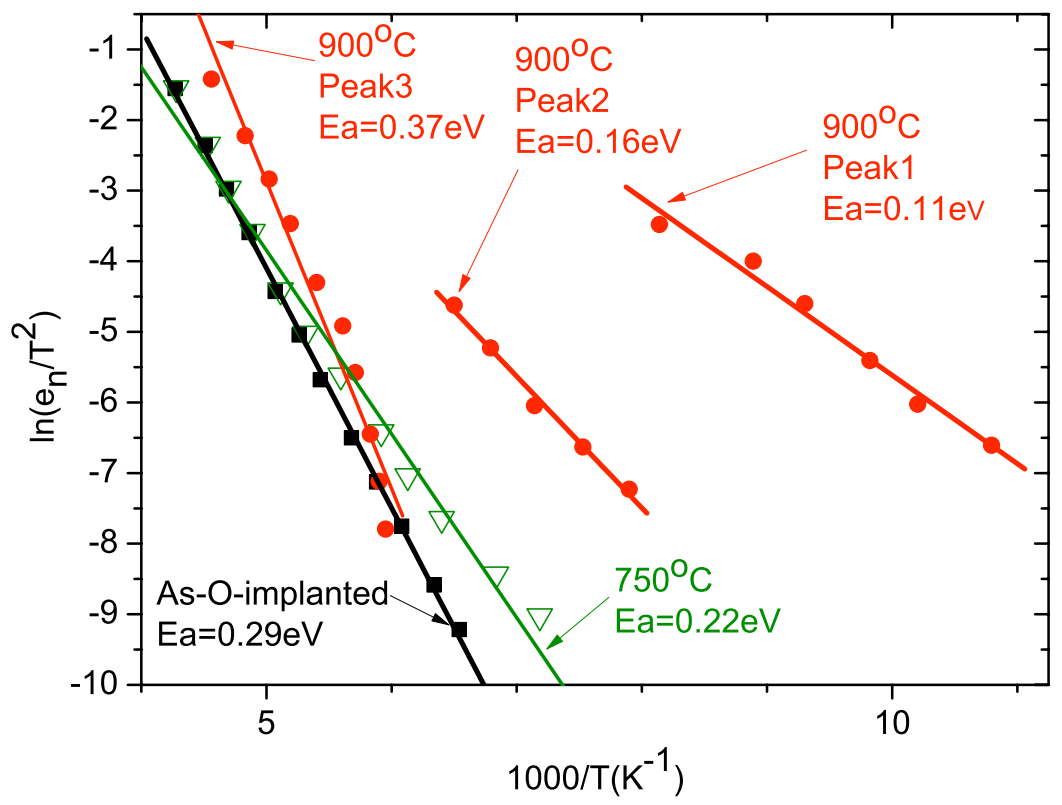

Figure 2(a)

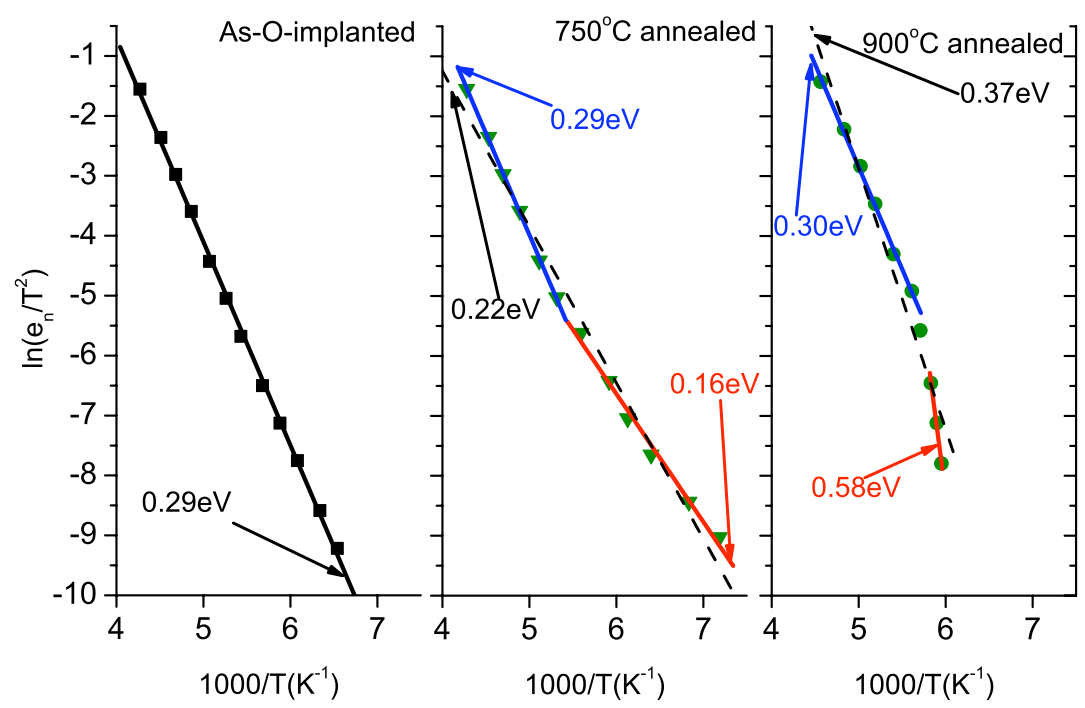

Figure 2(b) 


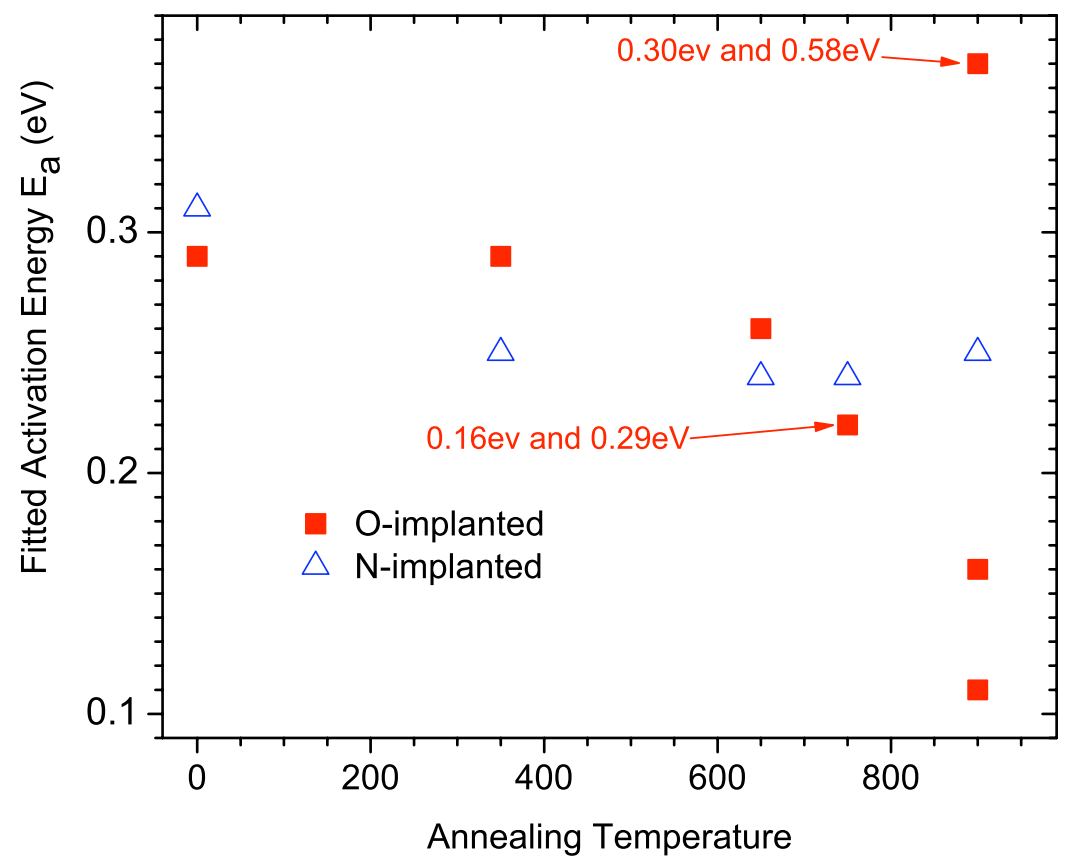

Figure 3 